\title{
Pulsed Radiofrequency of the Gasserian Ganglion as a Treatment of the Trigeminal Neuralgia Secondary to Herpes Zoster in Patients with Pacemaker: Case Report
}

\author{
Torres Huerta Juan Carlos ${ }^{1}$, Maya Rodríguez Iván David ${ }^{3}$, Tenopala Villegas Sergioº, Sandoval Mendoza Rosa \\ Adriana $^{3}$
}

${ }^{1}$ Staff Physician, Assistant Professor of the Interventional Algology in the Hospital Centro Médico Nacional 20 de Noviembre, Mexico

${ }^{2}$ Staff Physician, Assistant Professor of Algology Course in the Hospital Centro Médico Nacional 20 de Noviembre, Mexico

${ }^{3}$ Resident Physician in Algology, Hospital Centro Médico Nacional 20 de Noviembre, Mexico

Submission: March 07, 2018; Published: March 15, 2018

*Corresponding author: Juan Carlos Torres Huerta, Staff Physician, Assistant Professor of the Interventional Algology in the Hospital Centro Médico Nacional 20 de Noviembre, Cerro Gordo \#18 Colonia Campestre Churubusco C.P. 04200, Del. Coyoacán, Ciudad de México, mexco, Tel: +5215554086493 ; Email: drtorres@dolortech.mx

\begin{abstract}
Introduction: More and more patients with implanted cardiovascular electronic devices (pacemakers) are candidates for radiofrequency interventional procedures as a treatment for painful conditions. There are several considerations to take into account to avoid electromagnetic interference with these devices. We describe two clinical cases and perform a review of the existing literature on this topic.

Case description: A 89-year-old female and a 74-year-old male with a diagnosis of trigeminal neuralgia secondary to herpes zoster showing little response and tolerance to pharmacological management, both patients with cardiac pacemaker. After a medical examination, the device is reviewed by the cardiac electrophysiology service and indications are provided to proceed safely with the interventional treatment. Pulsed radiofrequency thermocoagulation of the Gasserian ganglion, under fluoroscopy and sedation, is done. Monitoring is performed during the procedure using ECG 6 Derivations, Sat02\% and non-invasive blood pressure (NIBP). The Visual Analogue Scale (VAS) was used to assess the intensity of pain. During the procedure, interference was observed in the electrocardiogram trace in both patients, which generated the activation of the pacemaker, with no relevance in the hemodynamic stability. Patients reported improvement in the control of neuropathic pain, achieving a decrease of pharmacological treatment.
\end{abstract}

Conclusion: Radiofrequency generates interference with pacemakers. This lack of knowledge can cause damage in these devices and fatal consequences for the patient. Proper preparation and knowledge of the type of device are essential to conduct this interventional procedure safely.

Keywords: Pulsed radiofrequency; Pacemakers; Trigeminal neuralgia; Gasserian ganglion

Abbreviations: RFP: Pulsed Radio Frequency; VAS: Visual Analogue Scale; NIBP: Non-Invasive Blood Pressure; bpm: Beats Per Minute; RF: Radio Frequency; HR: Heart Rate

\section{Introduction}

The chronic pain management has always been a great challenge for physicians. Pharmacological therapy has not provided good effectiveness rates in this type of pain, and the usefulness of this therapy is limited by the side effects in many cases. This has led to the search for other alternatives for the chronic pain management. Radiofrequency rhizolysis is one of the most commonly used interventional procedures for pain relief

in patients with trigeminal neuralgia. It aims to interrupt the impulses of the nerves that transmit painful sensations. Although it is an effective procedure, it is not free of complications [1]. Since the 1980s, a growing number of patients with implantable cardioverter defibrillators and pacemakers have come to pain management clinics for evaluation and treatment. The presence of these devices makes some therapy and procedures difficult due to the electromagnetic interference generated by such devices [2]. 
Despite technological advances, pacemakers are still susceptible to electromagnetic interference in ranges from 0 to $109 \mathrm{~Hz}$. Radiofrequency is included in this range. Different responses may result from this interaction, including inhibition or damage to electrical components [2]. For this reason, these devices must be deactivated or reprogrammed before some procedures, especially if the patient is dependent on them [2,3]. There are no specific guidelines for the use of radiofrequency in patients with pacemakers and, in general, the same considerations as those used with the electro-surgical scalpel are followed. This work makes a contribution to the experience in the management of patients with trigeminal neuralgia who require RF therapy of the Gasserian ganglion and patients with an electronic cardiac stimulation device.

\section{Study Description}

A report of two patients from the Pain Clinic Services, Hospital Centro Médico Nacional 20 de Noviembre, Mexico City, with cardiac pacemakers, trigeminal neuralgia secondary to herpes zoster and neuropathic pain refractory to conventional treatment was made.

\section{Clinical Case 1}

89-year-old female with neuropathic pain in the (V1, V2 and V3 branches) right hemifacial region secondary to herpes zoster, of a 1 year of development. The patient reported a Visual Analog Scale (VAS) pain score of $8 / 10$, little response and tolerance to the pharmacological management based on antiepileptic drugs. The patient is scheduled for right Gasserian ganglion block with pulsed radiofrequency. The patient has a cardiac pacemaker. Prior to the surgical procedure, the cardiac electrophysiology service's staff is asked to make an assessment to the patient. This staff performed the reading and review of the device, providing the following data: Biotronik $^{\mathrm{TM}}$ bicameral pacemaker, which was programmed in DDD mode, with a frequency of $60 / 1$. By decreasing the rate response of pacemaker, staff observed an intrinsic heart rate, with a heart rate (HR) of 60 beats per minute (bpm). They concluded that it is not necessary to reprogram the pacemaker or to deactivate it, since the patient is not dependent on it. The surgical procedure was performed under sedation and monitoring with 6-lead electrocardiogram (ECG), pulse oximetry and non-invasive blood pressure (NIBP). Under fluoroscopic guidance, the oval hole was located and a 10-cm 22-gauge RF needle with $10 \mathrm{~mm}$ active tip was inserted to the Gasserian ganglion. Correct location of the needle was verified by motor and sensory stimulation at 2 and 50 Hertz, respectively in the 3 branches. 2 cycles of pulsed radiofrequency (RFP) were performed for 180 seconds at $42^{\circ} \mathrm{C}$ in each trigeminal branch. At the moment of starting the pulsed radiofrequency procedure, interference was observed in the trace of the electrocardiogram, which generated the activation of the pacemaker without relevance in the hemodynamic stability of the patient, the procedure was completed without incident. The patient reported pain reduction immediately after the procedure with a VAS score of $3 / 10$. The pain is maintained with a VAS score of 3/10 at 4 weeks, achieving reduction of pharmacological treatment.

\section{Clinical Case 2}

A 74-year-old male with burning and stinging pain in the (V2 and V3 branches) right hemifacial region secondary to herpes zoster, of 8 months of development. The patient reported a Visual Analog Scale (VAS) pain score of $6 / 10$. At the beginning of the disease, the patient had a good response to drug treatment with antiepileptic drugs, but the pain increased in intensity with poor tolerance to the medications at 4 months of follow-up. It was decided to schedule the patient for a right Gasserian ganglion block with RFP.

The patient had a cardiac pacemaker, so the cardiac electrophysiology service's staff is asked to make an assessment to the patient. This staff performed the reading and review of the device, providing the following data: Boston Scientific ${ }^{\mathrm{TM}}$ bicameral pacemaker, which was programmed in DDDR mode, with a baseline radiofrequency of $50 \mathrm{bpm}$ and maximum radiofrequency $130 \mathrm{bpm}, 82 \%$ atrial pacing and $100 \%$ ventricular pacing. It was concluded that the patient is dependent on the pacemaker, it was suggested to reprogram the pacemaker to (DOO) asynchronous mode prior to the procedure. Patient underwent sedation and non-invasive monitoring. Under fluoroscopic guidance, the oval hole was located and a 10 -cm 22 -gauge RF needle with $10 \mathrm{~mm}$ active tip was inserted to the Gasserian ganglion. Correct location of the needle was verified by motor and sensory stimulation at 2 and 50 Hertz, respectively in the 3 branches. 2 cycles of pulsed radiofrequency (RFP) were performed for 120 seconds at $42^{\circ} \mathrm{C}$ in each right trigeminal branches V2 and V3. During the procedure, a slight interference was observed in the ECG trace without repercussions on hemodynamic stability. The patient reported pain reduction with a VAS score of $2 / 10$. Pain intensity remained in control one month after the procedure with a VAS score of 2/10. No complications were reported and pharmacological treatment was reduced.

\section{Discussion}

The electronic devices for cardiac stimulation (pacemakers, cardiac defibrillators, and cardiac synchronizers) are prone to suffer electromagnetic interference generated in other devices. $\mathrm{RF}$, which has been used in many pain management procedures for more than 50 years, generates this interference. This interference may vary from an unjustified cardiac stimulation, reprogramming, or even a complete inhibition of the pacemaker. In addition, this interference may produce heating of the electrode causing myocardial damage and raising the thresholds of stimulation and sensing [1].

In 2014, Barbieri published a cohort of 30 patients with implanted devices including pacemakers, cardiac defibrillators and spinal stimulators, who underwent different radiofrequency neurotomy procedures for the treatment of chronic pain. In this cohort, no patient had RF interference with the device. Patients 
with RF of the Gasserian ganglion were not included and most of the procedures were performed in the lumbar and sacral region [4]. In the literature, one case report [5] was found only, in which a rhizotomy of the Gasserian ganglion was successfully performed in a patient with atrial fibrillation who bearing a pacemaker. The authors suggest taking the necessary precautions such as reviewing and reprogramming the device before the surgical procedure, locating the pad as far as possible from the pacemaker and adequately monitoring the patient during the surgical procedure.

The cases we reported were carried out in a safe and successful manner following the recommendations from the guidelines of cardiology societies in pacemakers and cardiac stimulation devices. Although a slight interference caused by RF therapy was observed in the cardioscope tracing during the procedure, such interference was not of clinical relevance nor did it cause hemodynamic alterations in the patients. At the end of the surgical procedures, the devices continued to function properly. Based on our experience and in the review of the literature, we can suggest that patients with electronic cardiac stimulation devices, who benefit from an interventional treatment for pain with RF, either conventional or with pulsed RF, should be assessed as a whole in the preoperative period by the cardiology/electrophysiology services and determined whether or not they require the device to be reprogrammed. In the case of pacemakers, this is determined taking into account whether the patient is dependent on it or not. The pacemaker of device-dependent patients must be programmed in an asynchronous mode (A00/VO0/DO0) and non-dependent patients can be submitted to the procedure with adequate monitoring during the intraoperative, such monitoring could be more rigorous according to the clinical condition of the patient. The cardiopulmonary resuscitation equipment and specifically the percutaneous cardiac pacing pads should always be available in case of an emergency.

If monopolar RF is used, the plate should be located as far as possible from the device to reduce interference. Thanks to the fact that bipolar RF reduces and decreases the dispersion of energy between two needles, it may be indicated and be an interesting alternative in procedures where anatomy allows its use [6]. Unfortunately, it is not yet available in many places and in procedures, such as those reported by us, anatomy would limit its use. After the procedure, the patient must be evaluated and device should be reprogrammed to the initial mode. As a conclusion, we found that the radiofrequency used in the procedures for the relief of chronic pain, generates electromagnetic interference with the electronic cardiac pacing devices and the unawareness of this problem may generate a damage in these devices or interference in their operation with fatal consequences for the patient. Proper preparation and knowledge of the type of cardiac stimulation device are essential to safely and effectively perform this interventional procedure.

\section{Conflict of Interest}

The authors declare that they have no conflicts of interest.

\section{References}

1. Sluijter M, Racz G (2002) Technical Aspects of Radiofrequency. Pain Practice 2(3): 195-200.

2. Brignole M, Auricchio A, Barón Esquivias G, Bordachar P, Boriani G, et al. (2014) Guía de práctica clínica de la ESC 2013 sobre estimulación cardiaca y terapia de re sincronización cardiaca. Rev Esp Cardiol 67(1): 6-14.

3. Vardas P, Auricchio A, Blanc J, Daubert J, Drexler H, et al. (2007) Guías europeas de práctica clínica sobre marcapasos y terapia de re sincronización cardiaca. Rev Esp Cardiol 60: 1272.e1-1272.e51.

4. Barbieri M, Bellini M (2014) Radiofrequency neurotomy for the treatment of chronic pain: interference with implantable medical devices. Anaesthesiol Intensive Ther 46(3): 162-165.

5. Sun D, Martin L, Honey C (2004) Percutaneous Radiofrequency Trigeminal Rhizotomy in a Patient with an Implanted Cardiac Pacemaker. Anesthes Analg 99(6): 1585-1586.

6. Bautista A, Dadabayev A, Rosenquist E (2016) Bipolar Radiofrequency Neurotomy to Treat Neck and Back Pain in Patients with Automatic Implantable Cardioverter Defibrillator. Pain Physician 19(3): E505-E509.

Your next submission with Juniper Publishers will reach you the below assets

- Quality Editorial service

- Swift Peer Review

- Reprints availability

- E-prints Service

- Manuscript Podcast for convenient understanding

- Global attainment for your research

- Manuscript accessibility in different formats

( Pdf, E-pub, Full Text, Audio)

- Unceasing customer service

Track the below URL for one-step submission

https://juniperpublishers.com/online-submission.php 